\title{
Commonplace
}

\section{About The Commonplace}

\section{Quincy Childs}

Published on: Jun 29, 2020

DOI: $10.21428 / 6 \mathrm{ffd} 8432.7 \mathrm{c0c} 6319$

License: Creative Commons Attribution 4.0 International License (CC-BY 4.0). 
The Knowledge Futures Group ( $\underline{\mathrm{KFG}}$ ) is committed to building and sustaining open infrastructure for public knowledge that puts researchers in control of the tools they use everyday to solve society's biggest challenges. Our newest product, Commonplace, is a publication that invokes the title's Latin roots of locus communis to create a space where people discuss the digital infrastructure and policies needed to distribute, constellate, and amplify knowledge for the public good.

Commonplace brings together mission-aligned individuals, institutions, and organizations to contribute to the larger conversation about the many social implications of open and closed infrastructure: the distributed and centralized systems that undergird our modern modes of information sharing and communication. We will pinpoint emergent practices and new ways of thinking that benefit everyone. The mission of Commonplace is thus to reflect a multitude of viewpoints around what the future of knowledge should look like toward collective action and broader advocacy. We will integrate our resources across the KFG and with our partners to bring people together, build infrastructure, and advocate for a more sustainable and collaborative process for ongoing knowledge creation and data stewardship.

\section{So, how do we do this?}

How are knowledge infrastructures changing and how can we shape them for a shared future? By investigating, proposing, and interrogating what healthy knowledge futures can and should look like, we will open conversations toward action. Those conversations manifest and take shape right here. Commonplace will cultivate global voices to exchange views on the shared power of knowledge resources through circulating topics that span disciplines and industries:

- 'Information Disorder'

- bigdata theory. ( $\&$ this link)

- cognitive security



- disinformation around health

- fake news / information disorder

- media literacy

- online extremism

- post-truth politics

- sociotechnical security_(STsec).

- Data Ethics 
- algorithmic bias

- data justice, privacy, and rights

- public knowledge graphs

- racial equality in tech and publishing

- Open Infrastructure

- open access policies and technologies

- open data

- open source systems

- preprint servers

- Sustainability

- media pollution

- environmental disinformation ( $\&$ this link)

- eco-literacy

- environmental data justice

Please comment on this document to propose additional relevant topics.

Commonplace pieces embed multimedia to harness the full potential of discursive collaboration in a digital space-from annotated documents, letters, and reading lists, to dynamic interview and syndication series. Ultimately, these publication serve as a timely meditation for untimely facts, facilitating an exploration into how the concept of openness has shaped our everyday, and where it remains most necessary to implement.

To publish within Commonplace, see further information on our Contribute page! 